\title{
Osteotomy in Genioplasty by Piezosurgery
}

AQ1

AQ2

\author{
Dario Bertossi, MD, ${ }^{*}$ Massimo Albanese, MD, ${ }^{*}$ Carmen Mortellaro, MD, DDS, ${ }^{\dagger}$ \\ Luciano Malchiodi, MD, DDS, ${ }^{*}$ Narendra Kumar ${ }^{\ddagger}$ Riccardo Nocini, MD, ${ }^{\S}$ \\ and Pier Francesco Nocini, MD, DDS*
}

Background: The chin is the most prominent and median sector of the lower third of the face giving harmony to nose and lips. The authors present the application of piezoelectric scalpel for the correction of different chin deformities. The distinctive characteristics of this device allow the authors to avoid or reduce the immediate genioplasty complications.

Methods: Fifty-five patients of defective chin have been treated from January 2006 to April 2008. Intraoral genioplasty was performed during the correction of dentofacial dysmorphisms or associated with nasal surgery. The authors used a piezoelectric cutting device to perform different osteotomies and if necessary, interpositional graft was used to stabilize bony segments.

Results: Piezosurgery has been associated with a fewer number of postoperative complications, especially as regard intraoperative bleeding, nerve injuries (immediate and late), hematomas and seromas, asymmetry (immediate and early). The mean time for completing the complete procedure of genioplasty with piezosurgery was almost the same compared with the saw and drill. Conclusion: Genioplasty represents one of the most common ancillary procedures and may be associated with corrective surgery of dentofacial dysmorphisms. Mental nerve injuries, asymmetries, intraoperative bleeding are the main immediate complications of genioplasty. Distinctive characteristics of ultrasonic piezoelectric osteotomy are selective cut of mineralized structure with less risk of vascular and nervous damage (microvibrations), intraoperative precision (thin cutting scalpel and no macrovibrations), blood free site (cavitation effect). In the authors' experience, piezoelectric scalpel, compared with saw and drill, enables them to reduce or avoid immediate complications of chin surgery, helping the surgeon to reach patients' satisfaction.

A03 From the * Department of Surgery, Section of Oral and Maxillofacial Surgery, University of Verona, Verona; †Department of Health Sciences "A. Avogadro," University of Eastern Piedmont, Novara, Italy; $\ddagger$ Medical Institute, Faculty of Medical Science, Anglia Ruskin University, Chelmsford, UK; and §ENT Department, University of Verona, Verona, Italy.

Received January 25, 2018

Accepted for publication May 13, 2018

Address correspondence and reprint requests to Dario Bertossi, MD,

AQ4 Department of Maxillofacial Surgery and Dentistry, University of

Verona, University Hospital of Verona, Piazzale L.A. Scuro 10 - 37134

Verona, Italy; E-mail: Dario.bertossi@univr.it

This paper describes the experience of the Verona School in the use of Piezosurgery in the osteotomies performed during intraoral genioplasty, comparing results and complications with traditional rotating instruments.

QQ5 The authors report no conflicts of interest.

Copyright $\odot 2018$ by Mutaz B. Habal, MD

ISSN: 1049-2275

DOI: $10.1097 /$ SCS.0000000000004773
Key Words: Genioplasty, osteotomy, piezoelectric bone surgery, piezosurgery

(J Craniofac Surg 2018;00: 00-00)

The chin, occupying its very prominent position, is one of the elements that contribute to facial balance and harmony. The value of this area in the aesthetic perception of the face is well known: chin size and shape can determine the lower third proportions and a nice mandibular border profile. ${ }^{1-3}$ Many different genioplasty techniques have been described, most of those achieve the change in 1 single surgical step, whether with a chin implant, or with whatever the osteotomy. ${ }^{4-10}$

The actual trend in augmentation genioplasty is soft tissue allograft insertion ${ }^{11}$ due to its low morbidity and re-known short surgical time and morbidity, if compared with bone osteotomy with burr or reciprocating saw. Since 2000, Vercellotti introduced a new powerful piezoelectrical device ${ }^{12}$ which has been employed routinely for standard applications in different surgical fields thanks to its characteristics: ${ }^{13} 25-29 \mathrm{kHz}$ microvibrations allow a selective cut of the mineralized structures with no soft tissues damage, even in case of incidental contact. The micrometric vibration ensures also more precise cutting action than traditional saw and bur, making the instrument manageable and permitting major intraoperative control with a consequent increase in safety. The physical phenomenon of cavitation, associated with the micrometric vibrations, maintains a more blood-free site; the cavitation effect of current device does not appear to harm cell viability and differentiation more than conventional methods, and therefore normal reossification may be expected. ${ }^{14,15}$ Moreover, the relative lower intraoperative temperature produced by the device is associated with a less tissue and cellular damage. ${ }^{16}$

With this paper we want to address the piezosurgical osteotomic procedure that we believe can give the possibility of improving the followings on a long-term follow-up time:

1. the reduction of intraoperative complications such as bleeding, edema, unprecise osteotomic line particularly on the mandibular border area and the posterior mandibular cortical bone;

2. the extent of the bone section below the mental nerve to provide a good uninterrupted mandibular line in order to avoid stairstep deformity that can occur when the bone osteotomy is performed.

\section{METHODS}

The data of this study were gathered from 1 surgeon that used the same surgical technique and material on 55 cases of defective chin (34 females and 21 males) treated from January 2006 to April 2008; the mean age was 29.7 (range from 17 to 38 ). They were ranked in 2 different groups: 29 patients who underwent to the same procedure by Piezosurgery (group A) and 26 patients who underwent to genioplasty performed by reciprocating saw (group B). None of the patients were having any metabolic or physical relevant illness. Exclusion criteria included patients with history of taking bisphosphonates, smokers, hormonal replacement therapy, chronic 
corticosteroid therapy, history of osteoporosis, thyroid disease, diabetes mellitus, postmenopausal women, coagulation alterations, patients with any history of systemic, autoimmune, oncologic condition that would affect or for which treatment would affect bone and corrective tissue remodeling at local and systemic level; at last, psychiatric conditions that could interfere with treatment rendered. All the patients were exhaustively informed about the surgical procedure and its complications and all of them gave both verbal and written consent. The principles outlined in the Declaration of Helsinki have been followed. The research is exempt from approval of the local institutional review board being the piezosurgery and the materials a standard in the actual surgical procedure and no more experimental.

Clinical pictures (front, profile, $3 / 4$ views) and radiographs (Panorex, profile and antero-posterior cephalogram X-rays) were taken before the surgery. The surgical planning included clinical analysis and cephalometric study according to Arnett's analysis. ${ }^{17}$

We actually individualize the surgical treatment. Anyway we selected patients in whom we performed a mean $6 \mathrm{~mm}$ chin advancement $(5.7-6.3 \mathrm{~mm}$ ) and 1 to $2 \mathrm{~mm}$ chin bone lowering measured at the pogonion.

In group A we utilized a piezoelectric cutting device (Piezosurgery Medical II- Mectron spa, Carasco, Italy) with MT1-10. In group B we utilized a reciprocating saw (Stryker Core System), in the irrigation fluid was $\mathrm{NaCl}$ solution in both the groups.

\section{Surgical Technique}

All the surgeries have been performed by endotracheal anesthesia (nasal intubation).

After infiltration of $10 \mathrm{cc}$ of naropine $7.5 \mathrm{mg}$ plus adrenaline $0.5 \mathrm{~mL}$, vestibular incision by scalpel is performed. We then go through the muscles with a Colorado electrocautery tip at $25 \mathrm{~W}$ power, we undermine the periosteum with a Pritchard and make 3 bone marks by MT1-10 tip piezoelectrical device in group A, by a pencil in group B. Group A received a less extended undermining due to the fact that it does not damage the soft tissues.

The line of osteotomy must be performed at least $5 \mathrm{~mm}$ below the mental foramen in order to respect the roots of the mandibular teeth. ${ }^{18}$ In group A the entire procedure is performed by the piezoelectric device, without the aid of osteotomes to complete the splitting of bone surfaces. Bone cuts are done at power 6 and irrigation level 3. The pressure on the tip must be done with continuous shift as it allows the tip to clean and cut with continuous irrigation. It is clearly possible to feel the posterior cortical bone and that we reach the soft tissues which are never damaged by the tip reducing bleeding. On the contrary, in group B it is better to split the surfaces with osteotomes in order to avoid deepening the saw in soft tissues while on the posterior surface of the bony chin.

The most important areas to be cared are the mandibular margins below the mentalis nerve to avoid asymmetries after the osteotomy. At the completing of the procedure we even do not need the chisel to separate bone surfaces. We utilized $1 \mathrm{~g}$ of interpositional allografts (Bio-Oss-collagen, Geistlich Pharma, Wolhusen, Schweiz) in all of our procedures to fill all the residual empty spaces between bone surfaces. The mandibular bony segments were fixed with titanium miniplates (Osteomed 2.0 Orthognathic System, Glendale, CA) and screws (4 for each miniplate). The mucosa was sutured with reabsorbable suture (Vycril 4-0, Ethicon, Johnson\&Johnson, Somerville, NJ). During the perioperative management, the antibiothic terapy was endovenous ampicillin associated with sulbactam $(1 \mathrm{~g}$ three times a day), whereas pain was controlled with ketoprofen $100 \mathrm{mg}$ on request. The clinical follow-up was at $1,4,7,14$ (intraoral suture removal), 30 days, then 2,6 and 12 months. The radiological follow-ups were taken after 1 day and 6,12 , 24 months.
Bleeding has been calculated deducting the amount of saline solution used for intraoperative irrigation to the overall aspirated fluids. Length of surgery has been timed by a manual Hanhart chronometer: start time was the mucosa incision, end time was the completion of the mucosa suture.

Each Piezosurgery tip and saw were used for 1 surgery.

Labiomental sensibility was evaluated at each clinical control by pin brick sensation, static 2-point test, moving 2-point test.

\section{CLINICAL CASE}

A 28-year-old woman underwent chin surgery by Piezosurgery. She was affected by a defective chin (see Fig. 1A-D). Under general anesthesia, an intraoral genioplasty was performed associated with open rhinoplasty. The chin was lowered $2 \mathrm{~mm}$ and moved forward $6 \mathrm{~mm}$ (see Fig. 2A-D). Surgery time was 28'12". Intraoperative bleeding was $138 \mathrm{cc}$. See the pre and postop x-rays showing the precision of the bone osteotomy with piezo device (see Fig. 3A, B). At the surgery time, she referred a monolateral deficit of sensibility of the labiomental region, which was completely healed at the 60 day follow-up. No other complications were registered. See the result with harmonic profile (see Fig. 4A-D).

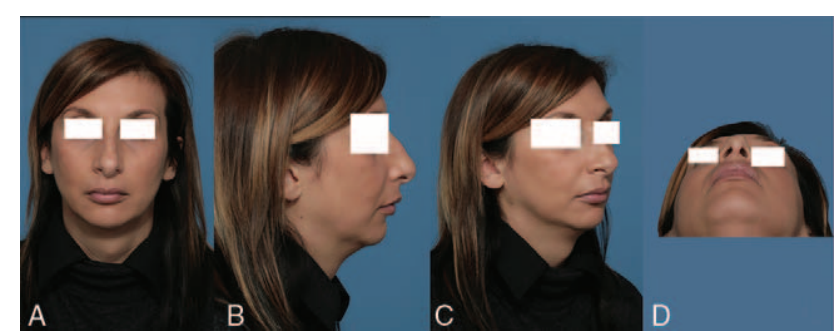

FIGURE 1. (A) Preop front view of the skeletal second class associated with AQ8 microgenia. (B) Preop side view of the patient where you can note the nasal hump and the microgenia. (C) Three-quarter preop view: overlong nasal tip and columellar exposure with weak chin. (D) Preop base view with deviated nasal tip on left side.

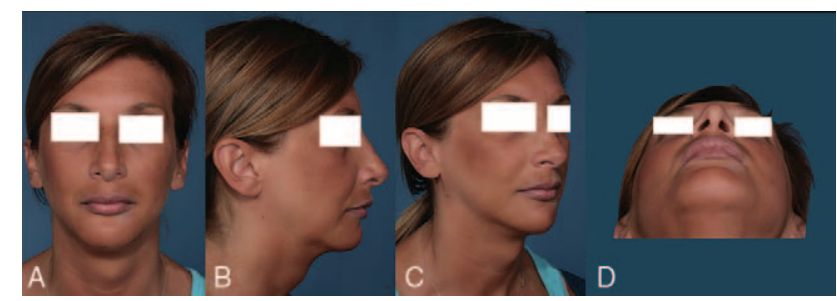

FIGURE 2. (A) Postop front view showing the harmonic projection of the chin. (B) Postop side view with good esthetic result reduction of the nasal hump and balanced profile. (C) Three-quarter view good result on the social profile. (D) Base view: asymmetry has been solved.

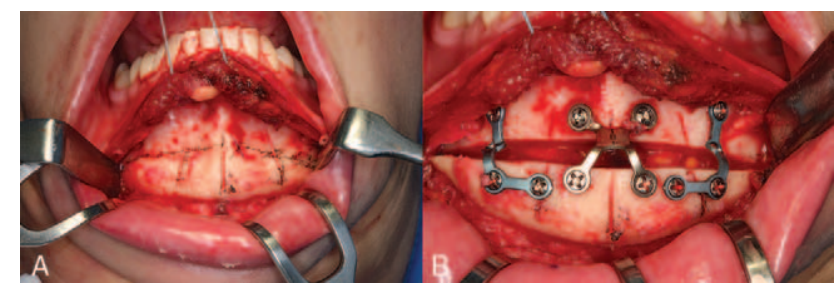

FIGURE 3. (A) Intraoperative preop view with reference lines. (B) Intraop view after bone fixation. 


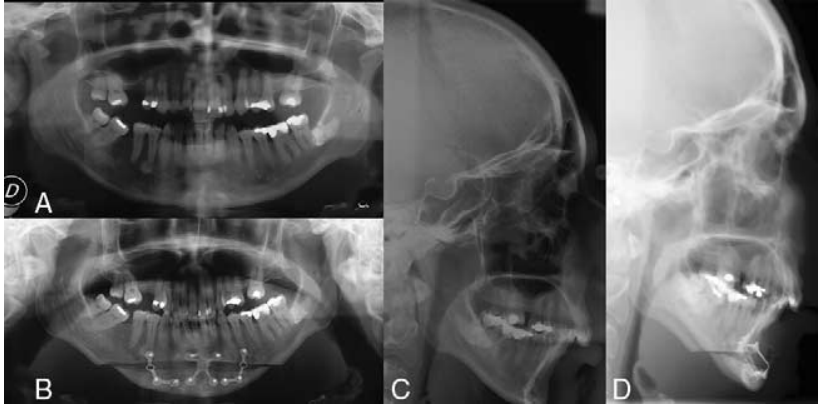

FIGURE 4. (A) Panoramic X-ray preop view. (B) Teleradiographic side view before surgery. (C) Panoramic X-ray after surgery. (D) Teleradiographic side view postsurgery.

\section{RESULTS AND DISCUSSION}

The mean time of surgery in group A was 27'53" (range between $23^{\prime} 14$ '" and 32'34) and for group B it was 25'13' (range to 21'35' and 28'05") (see Table 1).

In group A the intraoperative field was clearer and the osteotomy better visualized thanks also to the continuous irrigation of the Piezosurgery but without any spurts. The mean intraoperative valuated bleeding was $134 \mathrm{cc}$ in group $\mathrm{A}$ and $275 \mathrm{cc}$ in group B (see Table 2).

As regard postoperative complications, we utilized the classification by Guyuron ${ }^{19}$ that ranks them in 3 groups: immediate (day of surgery), early (at 15 days after surgery), and late (at 60 days after surgery) complications. The results were an overall reduction of the complication of the group A compared to group B, particularly as regard early and late asymmetry (1 patient group A instead of 5 patients in group B) and slight hematoma in the area under mentalis nerve foramen (1 patient in group A, 6 patients in group B). No patients had nerve injury, infection, seroma, wound dehiscence or gingival retraction, no displacement of implant. One patient of both group had permanent lip ptosis. A slight skin dumpling was documented in only 1 patient of group A.

The cost of each surgical tip for the piezo was 120 euros, and 100 euros for the saw.

\begin{tabular}{lccc}
\hline TABLE 1. Surgery Time & & & \\
\hline Time of Surgery & Shorter & Longer & Mean \\
\hline Group A & 5.23 & 8.55 & 7.31 \\
Group B & 3.25 & 8.03 & 6.55 \\
\hline
\end{tabular}

\begin{tabular}{|c|c|c|c|c|c|c|c|c|}
\hline Immediate & $\mathbf{A}$ & B & Early & $\mathbf{A}$ & B & Late & $\mathbf{A}$ & B \\
\hline $\begin{array}{l}\text { Intraoperative } \\
\text { bleeding }\end{array}$ & $*$ & $*$ & Infection & 0 & 0 & Lip ptosis & 1 & 1 \\
\hline Nerve injury & 0 & 0 & Hematoma & 1 & 4 & Asymmetry & 1 & 5 \\
\hline \multirow[t]{4}{*}{ Asimmetry } & 0 & 0 & Seroma & 0 & 0 & Gengival retraction & 0 & 0 \\
\hline & & & Asymmetry & 0 & 5 & Skin dumpling & 1 & 0 \\
\hline & & & $\begin{array}{l}\text { Wound } \\
\text { dehiscence }\end{array}$ & 0 & 0 & $\begin{array}{l}\text { Displacement of } \\
\text { implant }\end{array}$ & 0 & 0 \\
\hline & & & $\begin{array}{l}\text { Lip ptosis } \\
\text { (temporary) }\end{array}$ & 1 & 1 & Nerve Injury & 0 & 0 \\
\hline
\end{tabular}

It is world accepted that genioplasty is a very useful aesthetic procedure to improve the harmony of the lower third of the face. Porous polyethylene and solid silicone allografts are probably the widest used material to improve facial appearance ${ }^{20}$ and apart from some cases of displacement due to wide dissection or trauma, or infection, which can be solved by removal, we can easily do such an operation in about 15 to 20 minutes average time also under local anesthesia. The main reported problem that was observed in solid silicone allografts was bone resorption with long-term unaesthetic outcomes. ${ }^{21}$ The actual extended silicon allografts show a reduced resorption rate.

It is also true that bone osteotomies allow us to solve tridimensional chin defects, allowing achieving submentalis soft tissue stretching, without the risk to incurring in bone resorption or bone erosion due to the implant. ${ }^{22}$ Moreover bone genioplasty has proved to provide stable results. ${ }^{23}$

As regard bone genioplasty, both intraoral and extraoral approaches have been described in scientific literature: in our practice, genioplasty is usually performed by intraoral approach. Surgical genioplasty is a relatively simple technique that is performed for aesthetic refinement, but it is not free of complications. Piezosurgery allows us to avoid or to reduce some of those ones. In order to cut a thick bone such as the mandibular one, we have utilized the MT1-10 insert, that it is not the keener one $(0.75 \mathrm{~mm}$ instead of $0.35 \mathrm{~mm}$ if the MT1-10S) but it is a good compromise between breaking strength and thinness. The lateral bone extension of the mandibular border of the chin was cut without risk for damage of the closest soft tissues. Bone has been cut with the piezoelectric scalpel for all its thickness with need of using a chisel and hammer to complete the posterior osteotomy. This is possible because the insert does not cut the soft tissues differently from rotating instruments or reciprocating saw.

Seventeen patients of group A referred a mild deficit of sensibility (12 monolateral and 5 bilateral) at the labiomental region which disappeared at 1 month follow-up, whereas in group B 22 patients (14 bilateral and 8 monolateral) had mild to moderate deficit which disappeared at 3 months follow-up. At 2 years of follow-up, no patient was reporting a nervous deficit.

Regarding hematomas: just 1 patient in group A instead of 4 patients in group B; the hematomas disappeared after 20 days. It is our opinion that these data are strongly related to the selective cutting action of Piezosurgery which does not hurt the soft tissues. The minor incidence of asymmetry in group A confirms the clinical efficacy and precision. According to our opinion, this result is strongly related to the major precision of the osteotomy at the mandibular border: as a matter of fact, the less undermining and the absence of microvibration and the lower risk of soft tissue injury allow a better surgical control of the maneuver.

The incidence of the remaining complications (infections, wound dehiscence, lip ptosis, skin dumpling, and gingival retraction) has been almost the same in the 2 groups that indicates the different cutting instrument seems not to influence the soft tissue healing.

The mean time for completing the complete procedure of genioplasty with piezosurgery (mean value of 27'53") was almost the same compared with the saw and drill (mean value of $25^{\prime} 13^{\prime \prime}$ ): indeed, even though the piezoelectric cut is longer than the traditional one, many procedures in order to protect soft tissues can be avoided, with a gain of cutting precision. In our experience, learning curve for piezoelectric scalpel needs not more than 8 to 10 surgeries-considering that the only complication of an improper use of this instrument is the fracture of the insert.

The costs are $25 \%$ more for the piezo because they suggest a single-use tip for a single procedure. It is not a problem if we speak 
in terms of precision, better surgical control, and comfort to the patient in eventual local anesthesia.

\section{CONCLUSIONS}

In our experience, piezoelectric scalpel is an effective alternative to traditional rotating instruments in genioplasty. Piezoelectric cutting device, compared with traditional rotating instruments, enables us to reduce or avoid many complications (especially immediate and early ones) associated with this aesthetic surgical procedure. ${ }^{24-26}$

\section{REFERENCES}

1. McCarthy JG, Kawamoto HK Jr, Grayson BH, et al. Surgery of the jaws. In: McCarthy JG, ed. Plastic Surgery. Philadelphia, PA: WB Saunders; 1990:1188-1200

2. La Trenta GS. Facial contouring. In: Rees TD, La Trenta GS, eds. Aesthetic Plastic Surgery, vol. 2. Philadelphia, PA: WB Saunders; 1994: 809-819

3. Gonzales-Ulloa M. Quantitative principles in cosmetic surgery of the face (profileplasty). Plast Reconstr Surg 1962;29:186-198

4. Jones BM, Vesely MJ. Osseous genioplasty in facial aesthetic surgerya personal perspective reviewing 54 patients. J Plast Reconstr Aesthet Surg 2006;59:1177-1187

5. Driemel O, Kloss F, Roth B, et al. [Genioplasty alone and in combination: Long-term results with emphasis on sensitivity and photoanalysis]. Mund Kiefer Gesichtschir 2004;8:289-295

6. Luhr HG. Significance of the chin for the aesthetics of the face. Fortschr Kiefer Gesichtschir 1989;34:23-27

7. Rosen HM. Aesthetic guidelines in genioplasty: the role of facial disproportion. Plast Reconstr Surg 1995;95:463-469

8. Hoenig JF. Sliding osteotomy genioplasty for facial aesthetic balance: 10 years of experience. Aesthetic Plast Surg 2007;31:384-391

9. Ferreira dos Santos Junior J, Abrahão M, Gregório LC, et al. Genioplasty for genioglossus muscle advancement in patients with obstructive sleep apnea-hypopnea syndrome and mandibular retrognathia.

10. Bader G, Morais D. Piezosurgery for genioglossal advancement in treatment of obstructive sleep apnea syndrome. Rev Stomatol Chir Maxillofac 2008;109:375-378

11. Sati S, Havlik RJ. An evidence-based approach to genioplasty. Plast Reconstr Surg 2011;127:898-904
12. Vercellotti T. Piezoelectric surgery in implantology: a case report-a new piezoelectric ridge expansion technique. Int J Periodontics Restorative Dent 2000;20:358-365

13. Vercellotti T. Technological characteristics and clinical indications of piezoelectric bone surgery. Minerva Stomatol 2004;53:207-214

14. Chiriac G, Herten M, Schwarz F, et al. Autogenous bone chips: influence of a new piezoelectric device (Piezosurgery) on chip morphology, cell viability and differentiation. J Clin Periodontol 2005;32:994-999

15. Vercellotti T, Nevins ML, Kim DM, et al. Osseous response following resective therapy with piezosurgery. Int J Periodontics Restorative Dent 2005;25:543-549

16. Happe A. Use of piezoelectric surgical device to harvest bone grafts from mandibular ramus: report of 40 cases. Int J Periodontics Restorative Dent 2007;27:241-249

17. Arnett GW, Bergman RT. Facial keys to orthodontic diagnosis and treatment planning. Part I and II Am J Orthod Dentofacial Orthop 1993;103:299-312395-411

18. Hwang K, Lee WJ, Song YB, et al. Vulnerability of the inferior alveolar nerve and mental nerve during genioplasty: an anatomic study. $J$ Craniofac Surg 2005;16:10-14

19. Guyuron B. MOC-PS(SM) CME article: genioplasty. Plast Reconstr Surg 2008;121(4 suppl):1-7

20. Morera Serna E, Scola Pliego E, Mir Ulldemolins N, et al. Treatment of chin deformities. Acta Otorrinolaringol Esp 2008;59:349-358

21. Barnett MP. Labial incompetence: a marker for progressive bone resorption in Silastic chin augmentation. Plast Reconstr Surg 1997; 100:553-554

22. Matarasso A, Elias AC, Elias RL. Labial incompetence: a marker for progressive bone resorption in silastic chin augmentation. Plast Reconstr Surg 1996;98:1007-1014

23. Stefan Shaughnessy A, Mobarak KA, Høgevold HE, et al. Long-term skeletal and soft-tissue responses after advancement genioplasty. Am J Orthod Dentofacial Orthop 2006;130:8-17

24. Bertossi D, Galzignato PF, Albanese M, et al. Chin microgenia: a clinical comparative study. Aesthetic Plast Surg 2015;39:651-658

25. Bertossi D, Albanese M, Turra M, et al. Combined rhinoplasty and genioplasty: long-term follow-up. JAMA Facial Plast Surg 2013;15:192-197

26. Bertossi D, Albanese M, Nocini PF, et al. Sliding genioplasty using fresh-frozen bone allografts. JAMA Facial Plast Surg 2013;15: $51-57$ 


\section{SCS}

Journal of Craniofacial Surgery

Manuscript No. SCS-18-0146

Dear Author,

During the preparation of your manuscript for typesetting, some queries have arisen. These are listed below. Please check your typeset proof carefully and mark any corrections in the margin as neatly as possible or compile them as a separate list. This form should then be returned with your marked proof/list of corrections to the Production Editor.

\section{QUERIES: to be answered by AUTHOR}

\begin{tabular}{|l|l|}
\hline QUERY NO. & \multicolumn{1}{c|}{ QUERY DETAILS } \\
\hline$<$ AQ1 & $\begin{array}{l}\text { Please confirm whether surnames/family } \\
\text { names (red) have been identified } \\
\text { correctly in the author byline. }\end{array}$ \\
Please provide missing academic \\
degrees (for example MD, PhD, DDS, \\
etc. "Prof" will not be listed) for author \\
"Narendra Kumar" in order to conform \\
to style.
\end{tabular}


<AQ9> If you have color in your proof, please indicate whether you approve the color charge by returning the color agreement with your corrections. The color agreement can be found at http:// links.lww.com/SCS/A52. The price for the first color figure is $\$ 400$. The charge for each additional color figure is $\$ 100$. If you prefer black and white figures, please indicate so on your proof corrections. 